\title{
ABBREVIATIONS OF JOURNALS AND MODERN EDITIONS
}

AJPh $=$ American Journal of Philology

$A E=$ L'Année Épigraphique

$A N R W=$ Temporini Hildegard, ed., Aufstieg und Niedergang der römischen

Welt. Berlin: Walter de Gruyter. Ongoing publication series since 1972.

$C E=$ Buecheler, Franciscus, and Ernestus Lommatzsch, eds. 1897. Carmina

Latina Epigraphica. 3 vols. Leipzig: Teubner.

$C I L=$ Mommsen, Theodor, et al., eds. 1863-1986. Corpus Inscriptionum

Latinarum. Berlin: George Reimer.

$C P=$ Classical Philology

$C Q=$ Classical Quarterly

EoRE = Hastings, James, John A. Selbie, and Louis H. Gray, eds. 1908-

1926. Encyclopaedia of Religion and Ethics. 13 vols. New York: Charles

Scribner's Sons.

ILS = Dessau, Hermann, ed. 1892-1916. Inscriptiones Latinae Selectae. 5 vols.

Berlin: Weidmann.

$J R S=$ Journal of Roman Studies

$O C D=$ Oxford Classical Dictionary, 3 rd edition. See Bibliography under

Hornblower and Spawforth 1996.

$O E D=$ Oxford English Dictionary, cited here from the 2011 update of the online edition.

$O L D=$ Oxford Latin Dictionary. See Bibliography under Glare 1982.

$R E=$ Wissowa, Georg, et al., eds. Paulys Realencyclopädie der classischen

Altertumswissenschaft. 1894-1978. Stuttgart: J. B. Metzler.

TAPA $=$ Transactions of the American Philological Association

Trans. $=$ translation 
THIS PAGE INTENTIONALLY LEFT BLANK 